\title{
A model of proactive policing
}

Proc. Natl Acad. Sci. USA http://doi.org/ccmx

(2017)

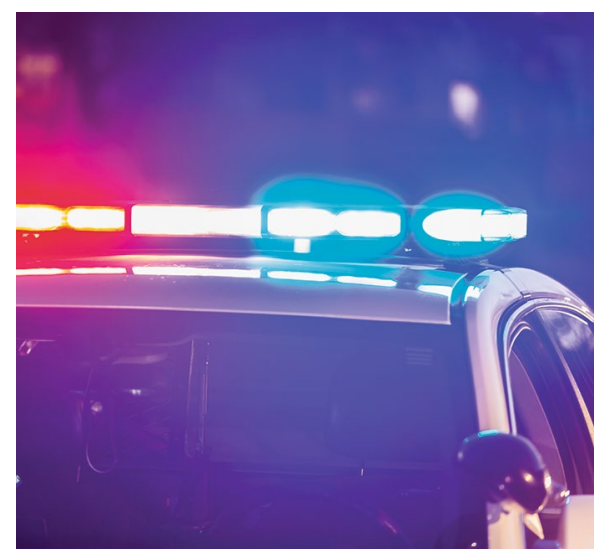

Credit: Kali9/iStock/Getty Images Plus/Getty

From contentions over the New York Police Department's stop, question and frisk (SQF) tactics adopted under Mayor Bloomberg, to increasingly publicized incidences of police brutality and shootings across America, police practices have come under scrutiny and spurred nationwide protests. Efforts towards police reform introduced by the Obama administration have, however, faced setbacks due to President Trump's emphasis on crime prevention in response to recent upticks in violence.

The apparent trade-off between public safety and community trust, both crucial aspects of effective policing, is the topic of a paper by Charles F. Manski and Daniel S. Nagin. The authors develop a formal model of lawful confrontational proactive policing - forceful crime prevention efforts that do not violate citizens' rights but still have social costs (for example, SQF). This optimal policing framework provides a structure for weighing the social benefits from crime reduction against the costs incurred from punishing offenders and violating the privacy of innocent people, and for analysing disparate impacts on racial and other groups. The authors take SQF tactics and the recent upsurge in homicides in Chicago as lenses through which to examine the model's policy implications. One conclusion is that certain groups may be net losers, even if a policy is socially optimal when summed over all groups.

Though the authors provide a means to dispassionately evaluate crime prevention policy, there remains the difficult problem of quantifying costs, especially those that cross into moral territory: for example, disproportionate enforcement against the innocent of certain racial groups may entail costs that society deems unacceptable, despite losses in benefits. Nonetheless this simple and transparent model offers a valuable benchmark against which to have these discussions.

\section{Sara Constantino}

Published online: 1 September 2017

DOI: $10.1038 /$ s41562-017-0194-2 